\title{
UMA ANÁLISE SOCIORRETÓRICA \\ DE INTRODUÇÕES \\ EM ARTIGOS ORIGINAIS \\ DA CULTURA DISCIPLINAR \\ DA ÁREA DE NUTRIÇÃO
}

\author{
UN ANÁLISIS SOCIO-RETÓRICO DE INTRODUCCIONES EN ARTÍCULOS ACADÉMICOS DE LA \\ CULTURA DISCIPLINARIA DEL ÁREA DE NUTRICIÓN
}

\author{
A SOCIO-RHETORICAL ANALYSIS OF INTRODUCTIONS IN ORIGINAL ARTICLES OF THE \\ NUTRITION AREA `S DISCIPLINARY CULTURE
}

Cibele Gadelha Bernardino*

Jorge Tércio Soares Pacheco**

Universidade Estadual do Ceará

RESUMO: O presente trabalho tem por objetivo apresentar como a área de Nutrição constrói e entende a seção de Introdução em artigos acadêmicos originais. Para isso, apoiamo-nos nas concepções teórico-metodológicas de Swales (1990), acerca dos gêneros acadêmicos, e nas descrições sociorretóricas de artigos experimentais, realizadas por Nwogu (1997) e Costa (2015) para a área de Medicina. Em relação à descrição da comunidade disciplinar em questão, adotamos o conceito de cultura disciplinar, postulado por Hyland (2000). Assim, nossa pesquisa de natureza exploratório-descritiva dispôs de um corpus de trinta artigos acadêmicos, distribuídos em seis periódicos da área de Nutrição e Saúde, indexados no banco de dados WebQualis da Capes. Conforme a análise, percebemos que a Introdução se mostrou uma seção concisa e objetiva; no entanto, relevante para a construção da configuração retórica de artigos acadêmicos originais, considerando que, nessa área, não há uma unidade retórica voltada exclusivamente para a revisão de literatura.

PALAVRAS-CHAVE: Análise sociorretórica. Cultura disciplinar. Área de Nutrição. Artigo acadêmico original. Unidade retórica de Introdução.

\footnotetext{
* Professora adjunta do Curso de Letras e do Programa de Pós-Graduação em Linguística Aplicada (PosLA) da UniversidadeEstadual do Ceará(UECE). E-mail: cibelegadelhab@gmail.com.

** Doutorando e Mestre pelo Programa de Pós-Graduação em Linguística Aplicada/PosLA da UECE. Professor da PrefeituradeFortaleza. E-mail: j_tercio@yahoo.com.br.
} 
RESUMEN: Este trabajo tiene como objetivo presentar como el área de Nutrición construye e comprende la sección de Introducción en artículos académicos originales. Para ello, nos basamos en las concepciones teóricas y metodológicas de Swales (1990), acerca de los géneros académicos, y en las descripciones socio-retóricas de artículos experimentales hechas por Nwogu (1997) y Costa (2015) para el área de Medicina. En cuanto a la descripción de la comunidad disciplinar en cuestión, adoptamos el concepto de cultura disciplinaria postulada por Hyland (2000). Por lo tanto, nuestra investigación de naturaleza exploratoriodescriptiva posee un corpus compuesto por treinta artículos académicos, distribuidos en seis publicaciones periódicas en el campo de la Nutrición y Salud, indexados en el banco de dados WebQualis de la Capes. De acuerdo con el análisis, nos dimos cuenta de que la Introducción se ha demostrado una sección concisa y objetiva, sin embargo, pertinente para la construcción de la configuración retórica de artículos académicos originales, en vista que, en esta área, no existe una unidad retórica dedicada exclusivamente a la revisión de literatura.

PALABRAS CLAVE: Análisis socio-retórico. Cultura disciplinaria. Área de la Nutrición. Artículo académico original. Unidad retórica de Introducción.

ABSTRACT: This study aims to present how the Nutrition area understands and construes the Introduction section in original academic articles. In this regard, we relied on Swales' theoretical and methodological conceptions (1990) about academics genres, and on Nwogu (1997) and Costa's (2015) socio-rhetorical descriptions to the area of Medicine. Regarding the description of the disciplinary community under study, we adopted the concept of disciplinary culture postulated by Hyland (2000). Therefore, our research, defined as a study of exploratory and descriptive nature, had a corpus of 30 original academic articles distributed within six Nutrition and Health journals, indexed in the WebQualis CAPES database. According to the analysis, we realized the Introduction was presented as a concise and objective rhetoric unit; however important in the rhetorical configuration of academic articles, considering there is not a rhetorical unit devoted specifically for literature review in this area.

KEYWORDS: Socio-rhetorical analysis. Disciplinary culture. Area of Nutrition. Original academic article. Rhetorical unity of Introduction.

\section{INTRODUÇÃO}

O estudo sobre gênero em ambiente acadêmico toma impulso com a proposta sociorretórica de Swales (1990), quando propõe o modelo CARS (Create a Research Space). Nessa proposta, o autor mostra-nos uma metodologia para descrição da configuração retórica da unidade de Introdução de artigos acadêmicos. Desde então, muitos trabalhos tomaram como norte sua proposta teóricometodológica e a expandiram para os mais diversos gêneros presentes na academia e em outros campos discursivos.

Nessa perspectiva sociorretórica, há alguns trabalhos que descrevem determinadas seções do artigo acadêmico, como os estudos de: Silva (1999), acerca dos Resultados e Discussão na área de Química; Hendges (2001), sobre a Revisão de literatura; Dias e Bezerra (2013), sobre Introduções na área de Saúde Pública; e Costa (2015), sobre um comparativo sociorretórico entre as culturas disciplinares das áreas de Linguística e Medicina. Em âmbito internacional, destacamos os estudos de: Nwogu (1997), sobre a organização retórica de artigos acadêmicos da área de Medicina; Amirian, Kassaian e Tavakoli (2008), sobre a seção de Discussão em artigos da área de Linguística Aplicada, entre outros trabalhos. Diante desse pequeno recorte de estudos acadêmicos, verificamos a ausência de pesquisas voltadas à organização retórica de artigos na área de Nutrição, tornando-se, assim, um campo fértil para nossa investigação.

Estudar a produção escrita, na academia, implica compreender o processo de produção, distribuição e consumo dos gêneros, tendo em vista que os textos são produzidos para serem compreendidos dentro de certos contextos culturais. Muitas vezes, as representações de dada cultura disciplinar não se apresentam somente na superfície textual, como, por exemplo, através do léxico específico ou do conteúdo abordado. Faz-se, pois, necessário um mergulho mais profundo nessa cultura para perceber como ela compreende e faz uso dos seus gêneros (HYLAND, 2000).

Bernardino \& Pacheco | Uma análise sociorretórica de introduçóes em artigos originais da cultura disciplinar.. 
Em consonância com os estudos do gênero em ambientes acadêmicos, nosso trabalho ${ }^{1}$ tem como propósito descrever a unidade retórica de Introdução $o^{2}$ em artigo acadêmico, compreendendo a sua configuração através da análise da cultura disciplinar da área de Nutrição, e, assim, entender como os valores e as crenças desta área disciplinar influenciam a percepção e a construção do referido gênero ${ }^{3}$.

Passemos, agora, aos pressupostos teóricos que embasaram nossa pesquisa.

\section{EVIDENCIANDO O GÊNERO ARTIGO ACADÊMICO}

Para Motta-Roth e Hendges (2010), o artigo acadêmico é uma publicação em periódicos especializados nas mais diversas áreas do conhecimento, cujo objetivo é mostrar resultados de um estudo sobre um determinado tema, representando, conforme Hyland (1997), o gênero mais requisitado pela comunidade acadêmica, na medida em que está a serviço da manutenção e da valorização de determinada cultura disciplinar.

De um modo geral, a obra de Swales lida com o gênero artigo científico, por ser considerado o gênero mais valorizado na academia. Swales (2004), ao revisitar seu modelo de unidades retóricas: Introdução, Métodos, Resultados e Discussão(IMRD), verificou que esse modelo tende a ser mais flexível, principalmente, na área das Ciências Humanas. Para o autor, o artigo acadêmico se divide em: teórico, experimental e, cada vez mais recorrente, artigo de revisão.

Em relação ao artigo teórico, Bernardino (2007) ressalta que seu principal objetivo é realizar uma discussão teórica, sem, necessariamente, recorrer à análise de dados. Já o artigo de revisão, de acordo com Swales (2004), tem por objetivo fazer uma discussão da literatura existente, concluindo com uma avaliação global. Por fim, o artigo experimental, conforme Bernardino (2007), corresponde àquele trabalho que analisa dados de qualquer natureza. Na cultura disciplinar da área de Nutrição, esse tipo de artigo é caracterizado como original, por apresentar dados inéditos. Conforme percebemos nas orientações dos periódicos da área, artigos originais são aqueles trabalhos que trazem contribuições de pesquisas inéditas, mostrando relevância temática, o alcance e o conhecimento para a área.

Autores como Hyland (2000) têm mostrado que a análise e a descrição de artigos, assim como de outros gêneros acadêmicos, precisam passar por um olhar cuidadoso acerca da relação entre a cultura disciplinar e a construção desses gêneros. Assim, neste artigo, nossa compreensão sobre os gêneros acadêmicos põe em evidência as diferenças disciplinares que dada área apresenta em sua configuração textual. Desta feita, apresentamos a seguir as proposições de Hyland (2000) acerca do conceito de cultura disciplinar.

\section{COMPREENDENDO CULTURA DISCIPLINAR}

Hyland (2000) indica que gêneros acadêmicos são meios pelos quais pesquisadores negociam cautelosamente posicionamentos e argumentações com seus pares. Logo, a escrita acadêmica reflete e representa os discursos recorrentes em sua cultura disciplinar. Em outras palavras, a escrita deve ser entendida como fruto de uma sociedade e não de um indivíduo apenas; ela depende das ações

\footnotetext{
${ }^{1}$ Nesta pesquisa, todos os sujeitos envolvidos assinaram um Termo de Consentimento Livre e Esclarecido, garantindo-nos o uso legal dos dados obtidos por meio das entrevistas e dos questionários, de acordo com o Comitê de Ética em Pesquisa - CEP da UECE - Universidade Estadual do Ceará, processo nº 067 1978/2014.

${ }^{2}$ Este estudo apresenta parte dos resultados de uma pesquisa maior, em que são descritas todas as unidades retóricas de exemplares do gênero artigo acadêmico da área de Nutrição; no entanto, devido à necessidade de um espaço maior para a apreciação desses dados, limitamo-nos à seção de Introdução.

${ }^{3}$ Nossa pesquisa e os demais trabalhos realizados no âmbito do Grupo de Pesquisa em Discurso, Identidade e Letramento Acadêmico (DILETA), coordenado pela Profa. Dra. Cibele Gadelha Bernardino, têm buscado construir um percurso metodológico que viabilize a análise e a descrição das culturas disciplinares, visto que Hyland (2000), embora apresente considerações relevantes sobre o conceito de cultura disciplinar, não propõe claramente um percurso metodológico que nos ampare na descrição destas culturas.
} 
dos membros de determinadas comunidades. Assim, para o autor, compreender uma disciplina implica compreender seus discursos. Barwarshi e Reiff (2013) acrescentam que as ideologias de dada cultura acadêmica não estão imbricadas apenas nos gêneros acadêmicos; as crenças e valores se revelam nas demais atividades docentes, tais como orientações sobre atividades, comentários dos professores, além dos programas de curso.

No entanto, esse olhar para variações disciplinares, segundo Hyland (2000), é relativamente novo, levando em consideração que o empreendimento investigativo estava voltado para o estudo do gênero em detrimento da disciplina, valorizando substancialmente as semelhanças mais que as diferenças. Nessa perspectiva, Motta-Roth e Hendges (2010) chamam-nos a atenção para o fato de que compreender claramente os gêneros mais comumente utilizados em dada área disciplinar faz-se cada vez mais necessário, se o objetivo for produzir textos acadêmicos de forma eficaz.

Conforme Hyland (2000), cada disciplina carrega um conjunto de marcas que a caracteriza e a particulariza frente às demais áreas. Tais características não se apresentam somente no léxico específico, tampouco no conteúdo que se aborda, mas, profundamente, na maneira de conduzir, mostrar e conceber o conhecimento. Essas culturas diferem, ainda, na constituição de seus objetivos, através das relações de poder e interesses políticos, e no modo como estruturam e fundamentam seus argumentos. De acordo com o autor, os indivíduos de dada cultura disciplinar precisam adquirir competências discursivas especializadas para corresponder às expectativas da área disciplinar, e, assim, poderão ser considerados membros efetivos da referida comunidade.

Para Hyland (2000, p. 9), "[...] disciplinas são instituições humanas em que as ações e entendimentos são influenciados pelas relações pessoais e interpessoais, bem como pelas relações socioculturais e institucionais”" Corroborando essas assertivas, Bhatia (2004, p. 32), ao verificar diferenças em livros didáticos em Economia e Ciências Sociais, indica que "os gêneros são sensíveis a variações disciplinares"

Em suma, Hyland (2000) propõe que o conceito de cultura disciplinar venha contribuir para a mudança na maneira de compreender a escrita acadêmica, não mais se restringindo ao plano das ideias e das abstrações, mas concebê-la no mundo das práticas concretas e crenças sociais. Assim, passemos aos modelos sociorretóricos que embasaram nossa análise.

\section{APRESENTANDO MODELOS SOCIORRETÓRICOS DA SEÇÃO DE INTRODUÇÃO}

Swales (1990) aponta o modelo CARS (Create a research space) como uma contribuição metodológica relevante para a análise de gêneros, a qual permite analisar estratégias de construção desses gêneros por parte de seus escritores e/ou produtores. O modelo permite ao analista encontrar um percurso metodológico que promove uma descrição sociorretórica com base na composição textual prototípica dos gêneros.

Nesta pesquisa, verificamos a organização retórica ${ }^{6}$ de Introduções em artigos acadêmicos com base nas propostas de Nwogu (1997), sobre a análise de Introduções de 15 artigos na área da Medicina, em periódicos internacionais, e de Costa (2015), em 10 artigos, também, da área de Medicina, em periódicos brasileiros, mostrando-nos escolhas retóricas mais próximas à cultura disciplinar que nos propomos investigar, a área de Nutrição. Vejamos os movimentos retóricos ${ }^{7}$ elencados por Nwogu (1997) para essa unidade retórica:

\footnotetext{
4 "Disciplines are [in short,] human institutions where actions and understandings are influenced by the personal and interpersonal, as well as the institutional and sociocultural" (HYLAND, 2000, p. 9).

5 “[...] genres [at the same time], are sensitive to disciplinary variations...” (BHATIA, 2004, p. 32).

${ }^{6}$ Compreendemos este conceito como a distribuição e a organização das unidades informacionais recorrentes que respondem diretamente aos propósitos interacionais dos grupos sociais que utilizam gêneros.

${ }^{7}$ Swales e Feak (2000) definem movimento como um termo funcional que se refere a um ato comunicativo definido e delimitado, que é projetado para alcançar um objetivo principal comunicativo. Conforme Swales (2004), os movimentos são unidades retóricas que exercem uma função comunicativa coerente, seja em um
} 
Quadro 1: Movimentos e suas funções discursivas - Seção de Introdução

\author{
Movimento 1 - Apresentando informações gerais \\ (1) Referência ao conhecimento estabelecido no campo \\ (2) Referência aos principais problemas de pesquisa \\ Movimento 2 - Revisando pesquisas relacionadas \\ (1) Referência à pesquisa anterior \\ (2) Referência às limitações da pesquisa \\ Movimento 3 - Apresentando nova pesquisa \\ (1) Referência aos objetivos da pesquisa \\ (2) Referência ao principal procedimento de pesquisa
}

Fonte: Nwogu (1997, p. 135) ${ }^{8}$

De acordo com Nwogu (1997), no movimento 1, Apresentando informações gerais, as informações gerais são expostas, fazendo um convite ao estudo que se apresenta. Mostra-se o conhecimento tido como verdade por longo tempo e destaca-se o principal problema de investigação. Nwogu (1997) não traz um maior detalhamento acerca dos passos que compõem esse movimento, por isso recorremos à releitura de Costa (2015) em sua pesquisa sobre artigos experimentais da área de Medicina, publicados em periódicos nacionais.

Costa (2015) chama a atenção para o fato de que o primeiro passo, Referência ao conhecimento estabelecido no campo, do movimento 1, Apresentando informações gerais, em seu corpus, foi desconsiderado, tendo em vista que o segundo passo, Referência a limitações de pesquisas, do movimento 2, Revisando pesquisas relacionadas, contempla estudos anteriores como também o conhecimento considerado consolidado no campo de pesquisa. Já o segundo passo, Referência aos principais problemas de pesquisa, do movimento 1, Apresentando informações gerais, não se mostrou recorrente, embora, em alguns exemplares, tal passo tenha sido construído, de forma ampla e detalhada, indicando os problemas de pesquisa.

Conforme Nwogu (1997), o movimento 2, Revisando pesquisas relacionadas, contribui para o desenvolvimento do estudo, mostrando que a pesquisa se insere dentro de um contexto de obras consagradas, mas que deixaram certas lacunas. Esse movimento coloca a nova pesquisa dentro do contexto da investigação no campo em que se insere e é composto por dois passos: Referência à pesquisa anterior e Referência às limitações de pesquisa.

O primeiro passo, Referência à pesquisa anterior, desse movimento pode-se realizar por meio da identificação nominal do autor, pelo uso de nomes comuns quando se referem à identificação de pesquisadores, e através da referência a resultados ou generalizações de pesquisas anteriores. Costa (2015, p. 178) confirma tais informações, ao perceber que esse passo se evidencia pela citação de autores diretamente, bem como pela citação numérica que direciona o leitor à unidade de Referências, ou por meio das duas estratégias simultaneamente. Para a autora, esse passo estabelece que a pesquisa, em questão, deriva de trabalhos consolidados.

discurso oral ou escrito. Por mais que tais unidades retóricas possam ser alinhadas por meio de traços gramaticais, os movimentos são flexíveis em termos de sua realização linguística.

8 "Introduction

Move 1: Presenting Background Information:

by (1)Reference to established knowledge in the field.

(2)Reference to main research problems.

Move 2: Reviewing Related Research:

by (1)Reference to previous research.

(2)Reference to limitations of previous research.

Move 3: Presenting New Research:

by (1)Reference to research purpose.

(2)Reference to main research procedure." (NWOGU, 1997, p. 135). 
Já o segundo passo, Referência às limitações da pesquisa, é realizado através de uma avaliação negativa ou de uma lacuna em pesquisas anteriores (NWOGU, 1997). Confirmando esses dados, Costa (2015) mostra que tal passo traz à tona a incipiência de pesquisas anteriores, salientando lacunas teóricas existentes.

No movimento 3, Apresentando nova pesquisa, a principal função é introduzir a nova pesquisa, declarando os seus propósitos. O movimento também apresenta informação, indicando os métodos primários da investigação adotada no estudo. Também pode se fazer referência à amostra dos dados na qual o estudo é baseado. No entanto, sua maior ênfase se configura no propósito da pesquisa. O passo 1, Referência aos objetivos da pesquisa, apresenta-se por meio de lexemas explícitos, como por exemplo, "o objetivo dessa investigação [...]" (NWOGU, 1997, p. 128)9 . Já o segundo passo, Referência ao principal procedimento de pesquisa, foi desconsiderado no corpus de Costa (2015), tendo em vista que, na área de Medicina, há uma unidade retórica típica para apresentação de aspectos metodológicos.

Baseando-se nos movimentos retóricos propostos por Nwogu (1997), Costa (2015) apresenta um modelo cuja terminologia tenta indicar explicitamente a função dos movimentos e dos passos retóricos. Vejamos o modelo sociorretórico proposto por Costa (2015).

Quadro 2: Descrição retórica da unidade de Introdução de artigos experimentais da cultura disciplinar da área de Medicina

Movimento 1 - Apresentando o tema
Passo 1 - Fazendo referência a pesquisas prévias e/ou
Passo 3 - Indicando limitações de pesquisas prévias e
Movimento 2 - Apresentando os objetivos da pesquisa

Fonte: Costa (2015, p. 188).

Depois da apresentação dos pressupostos teóricos que nortearam nossa análise, passemos, então, ao percurso metodológico adotado no estudo.

\section{METODOLOGIA}

A nossa pesquisa se define como um estudo de natureza exploratório-descritiva, cuja análise dos dados se mostra de base qualitativa e quantitativa, visto que buscamos compreender a cultura disciplinar da área de Nutrição no que se refere à produção do gênero artigo acadêmico, percebendo a recorrência/prototipicidade dos movimentos e passos retóricos caracterizadores do referido gênero. No estudo, foram envolvidos 7 (sete) membros experientes ${ }^{10} \mathrm{em}$ dois programas de Pós-Graduação na área de Nutrição, um do estado do Ceará (CE) e o outro de São Paulo (SP). Com os participantes do primeiro programa, realizamos entrevistas pessoalmente, enquanto, com o segundo programa, por questões temporais, financeiras e geográficas, utilizamos questionários via e-mail. As entrevistas e os questionários foram conduzidos a partir de um roteiro previamente elaborado sobre a produção acadêmica na área investigada.

O corpus de nossa pesquisa se constitui de 30 exemplares do gênero artigo acadêmico original da cultura disciplinar da área de Nutrição $^{11}$, publicados entre 2008 e 2015, em seis periódicos da área de Nutrição e da grande área da Saúde, a saber: a Revista de

\footnotetext{
9 “The objective of the current investigation [...]” (NWOGU, 1997, p. 128).

${ }^{10}$ Professores/pesquisadores que compõe o corpo docente de um programa de Pós-Graduação na área de Nutrição, pois, para ser membro de um programa de PósGraduação, faz-se necessário apresentar fluxo contínuo de publicações de artigos acadêmicos em periódicos pertinentes ao campo de atuação, o que justifica, assim, nossa exigência em captar o olhar do pesquisador experiente no que se refere à produção de pesquisa acadêmica.

${ }^{11}$ Os artigos do corpus foram etiquetados em AAON (Artigo Acadêmico Original de Nutrição), recebendo uma numeração do 1(um) a 30(trinta).
} 
Nutrição, Nutrire, Alimentos e Nutrição, Cadernos de Saúde Pública, Scientia Medica e a revista Epidemiologia e Serviços de Saúde. A estratificação dos referidos periódicos varia do qualis B1 ao B5, conforme WebQualis CAPES (2015).

Hyland (2000), apesar de propor fundamentos teóricos consistentes sobre o conceito de cultura disciplinar, não apresenta claramente um caminho metodológico que proporcione a compreensão do conjunto de crenças e valores que permeiam uma determinada área. Considerando tal fato, o nosso estudo e as demais pesquisas realizadas no âmbito do Grupo DILETA estão em um processo de construção de um percurso metodológico que objetiva viabilizar a investigação de culturas disciplinares.

Assim, para a descrição da cultura disciplinar da área de Nutrição, tomamos, inicialmente, como parâmetro estudos que contextualizam historicamente a área de Nutrição no Brasil e trabalhos que versam sobre o perfil do profissional da área de Nutrição, materiais disponíveis em sites de associações, conselhos regionais e federal, entre outros. Em um segundo momento dessa descrição, pautamo-nos em relatórios da CAPES, que regulam e avaliam a área de Nutrição, no que se refere aos Programas de Pós-Graduação. O terceiro momento caracterizou-se pela descrição das orientações dos periódicos acerca da produção acadêmica, principalmente, para o artigo original. A última etapa da descrição consiste na apreciação do olhar de expertise dos membros experientes da área. É relevante sublinharmos que a descrição das orientações dos periódicos e as informações fornecidas pelos membros experientes correspondem aos elementos primordiais na articulação da análise linguístico-textual com a cultura disciplinar da área em estudo.

Para a análise linguístico-textual, nós nos apoiamos nos modelos retóricos de Nwogu (1997) e Costa (2015) sobre artigos acadêmicos da área de Medicina, uma vez que não possuíamos um referencial específico para a área de Nutrição. Tendo em vista que nossa proposta investigativa levou em consideração não apenas a análise linguístico-textual, mas principalmente a contextual, de base mais etnográfica (ASKEHAVE; SWALES, 2009, p. 240), fez-se constante um caminho de intersecções e cruzamentos entre os dados da literatura com os dados da cultura disciplinar, para que compreendêssemos como as unidades retóricas, bem como os seus movimentos e passos são/foram construídos para realizar os propósitos comunicativos dentro da cultura disciplinar. Para finalizarmos a descrição sociorretórica dos artigos acadêmicos originais, catalogamos, ainda, os itens léxico-gramaticais mais representativos de cada unidade informacional presentes na unidade retórica de Introdução.

Após a apresentação das escolhas e do percurso metodológico adotado em nesta pesquisa, passemos, agora, à apreciação dos resultados obtidos.

\section{RESULTADOS E DISCUSSÕES}

Nesta unidade retórica, apresentamos, inicialmente, uma descrição da cultura disciplinar da área de Nutrição, levando em consideração os documentos que regulam e orientam a área enquanto Programa de Pós-Graduação, as orientações dos periódicos sobre a produção acadêmica, como também o olhar de expertise dos membros experientes da área em estudo. Após essa descrição, analisamos sociorretoricamente a seção de Introdução dos artigos da referida área, à medida que entrelaçamos os dados dos textos analisados com os dados descritos na cultura disciplinar.

\subsection{DESCREVENDO A CULTURA DISCIPLINAR DA ÁREA DE NUTRIÇÃO NO BRASIL}

Conforme Diretrizes Curriculares Nacionais do Curso de Graduação em Nutrição (2001), o nutricionista é um profissional de saúde com formação generalista, humanista e crítica, e, dessa maneira, está apto a trabalhar em todas as áreas do conhecimento em que a alimentação e a nutrição se apresentem fundamentais à promoção, à manutenção e à recuperação da saúde, como também à prevenção de doenças de indivíduos ou grupos populacionais.

A área de Nutrição no Brasil é relativamente nova, considerando que o primeiro curso de Nutrição foi criado, somente, em 1939, na Faculdade de Saúde Pública da Universidade de São Paulo. A partir dessa época, várias regulamentações foram sancionadas com a finalidade de orientar, disciplinar e fiscalizar o exercício profissional, impulsionando, assim, a criação de vagas no Ensino Superior e a expansão da profissão para os mais diversos setores da sociedade (CFN, 2014). 
No que se refere aos Programas de Pós-Graduação da área de Nutrição no Brasil, somente a partir de 2011, os referidos programas se desvinculam da área de Medicina II, denotando, assim, que a área em estudo ainda apresenta forte ligação com a área de Medicina. Assim, visando a um melhor desempenho da área de Nutrição, o PNPG ${ }^{12}(2011$ - 2020) vislumbra um crescimento no número de programas nesse decênio, e, para isso, vem estimulando o fortalecimento dos programas já existentes e a criação de novos em regiões com maior carência (CAPES, 2013a). Acreditamos que tal postura venha solidificar ainda mais os programas de Nutrição como área disciplinar independente.

Dando continuidade à descrição da cultura disciplinar da área de Nutrição, tomamos como base de dados as orientações dos periódicos no que concerne à produção de seus trabalhos. As revistas envolvidas em nossa análise são: Revista de Nutrição, Nutrire, Alimentos e Nutrição, Scientia Medica, Cadernos de Saúde Pública e Epidemiologia e Serviços de Saúde, todas nacionais.

De acordo com as orientações dos periódicos, podemos evidenciar que há um interesse maior por artigos experimentais, conhecidos na área por artigos originais, justificando-se tal interesse devido ao ineditismo dos dados que esses trabalhos apresentam.

No que se refere às orientações para a construção da unidade retórica de Introdução, a Revista de Nutrição indica a pertinência de uma revisão de literatura adequada à apresentação do tema; no entanto, orienta que tal unidade não deve ser extensa, a não ser em artigos de revisão. Em consonância com essa revisão de literatura, a revista Alimentos e Nutrição orienta o autor a mostrar a relevância e a delimitação do assunto abordado. Ao desenhar o tema em estudo, o autor, de acordo com a revista Cadernos de Saúde Pública, pode ainda apresentar lacunas teóricas que justificam a realização de seu estudo, mas o autor deve limitar-se apenas àquelas referências que se ligam à sua investigação.

Para a Revista de Nutrição, tais citações devem ser numeradas consecutivamente à medida que são mencionadas no texto, compondo, assim, uma listagem de referências no final do artigo, conforme as recomendações estabelecidas pelo ICMJE ${ }^{13}$, conhecidas como estilo Vancouver. É importante frisar que todos os periódicos estudados seguem essas orientações. Conforme Pereira (2014), as normas de Vancouver constituem uma uniformização mundial no que se refere às publicações científicas na área da Saúde, justificando a necessidade dos periódicos nacionais de se submeterem aos padrões exigidos pela comunidade científica internacional.

A revista Scientia Medica, de acordo com o ICMJE, orienta que, na Introdução, o autor deve apresentar a natureza do problema e o seu significado. Já a revista Nutrire, nessa seção retórica, indica que se faz importante informar as hipóteses iniciais, caso existam, e, por fim, apresenta a necessidade de esclarecer os objetivos da pesquisa. A revista Cadernos de Saúde Pública acrescenta, ainda, que, se possível, faz-se pertinente o uso de verbos no infinitivo. Assim, os periódicos orientam que a unidade retórica de Introdução deve ser finalizada com a apresentação clara dos propósitos e objetivos da pesquisa.

A revista Epidemiologia e Serviço de Saúde recomenda ao autor apresentar o problema da pesquisa, sua justificativa e o objetivo, necessariamente, nessa ordem. Em linhas gerais, os periódicos recomendam que, na Introdução, os autores devem ser breves e concisos, estabelecendo dimensões bem definidas para a referida unidade retórica, como, por exemplo, a revista Nutrire e a revista Alimentos e Nutrição, que se mostram incisivas ao limitarem as dimensões da Introdução, entre seis e oito parágrafos, aproximadamente.

Após essas orientações, passemos ao olhar dos membros experientes da área de Nutrição, mostrando como eles percebem e compreendem a unidade retórica de Introdução em artigos originais.

No que diz respeito à seção de Introdução, os membros experientes consideram importante fazer uma apresentação do assunto relacionado ao trabalho, realizando um levantamento da literatura disponível, como também mostrando um pouco do "estado da

\footnotetext{
${ }^{12}$ Plano Nacional de Pós-Graduação.

${ }^{13}$ International Committee of Medical Journal Editors.
} 
arte" (Colaborador - C3) ${ }^{14}$. Para o C7, a apresentação do tema tem como propósito "fazer uma ponte entre a familiaridade do autor com o assunto e o provável desconhecimento do leitor com cada um dos diversos elementos que levaram os autores a empreender a pesquisa publicada”. Por sua vez, o C6 acredita que essa apresentação tem como finalidade “introduzir o assunto relacionado ao trabalho, mostrando as evidências disponíveis na literatura e defendendo a importância do trabalho atual”. Corroborando esses dados, o C5 sugere que o autor, por meio dessa apresentação temática, pode "dar conhecimento teórico para o entendimento do artigo". O C3 salienta que os autores também lançam mão de pesquisas oriundas de órgãos nacionais e internacionais, como OMS, UNICEF, Sociedade Brasileira de Hipertensão, entre outros.

Na exposição do tema, devem-se evidenciar as lacunas teóricas existentes, como também deixar claro o problema de pesquisa, como expressou o C1. Ao estabelecer a sua problematização, o autor deve mostrar claramente os objetivos do seu estudo, contextualizando-o dentro da temática apresentada, e, assim, justificar a relevância de seu trabalho (C3). Para o C4, em uma Introdução, “[...] não pode deixar de ter [...] a contextualização do objeto de estudo e a relevância do que você está propondo". O C3 volta a dizer que, nessa seção, o autor tenta convencer o leitor de que seu artigo é importante, embora chame a atenção de que essa seção deve primar pela concisão, não sendo necessário se estender por mais de uma página para mostrar os objetivos e a relevância do estudo proposto. Já o C2 indica, sinteticamente, que, nessa seção, “a problematização do tema, as lacunas e os seus objetivos” não podem faltar.

Acreditamos que esse percurso descritivo da cultura disciplinar da área de Nutrição vem possibilitar entender como essa área em estudo compreende, produz e se utiliza do gênero artigo acadêmico, proporcionando, assim, uma melhor compreensão sobre a razão subjacente (SWALES, 1990), que orienta a configuração sociorretórica da unidade retórica de Introdução do referido gênero. Desse modo, passemos à análise de tal unidade dos artigos acadêmicos originais da área de Nutrição.

\subsection{DESCREVENDO A UNIDADE RETÓRICA DE INTRODUÇÃO EM ARTIGOS ORIGINAIS DA ÁREA DE NUTRIÇÃO}

Embora a seção de Introdução seja considerada relevante na construção de artigos acadêmicos na área de Nutrição, tanto os membros experientes da área quanto os periódicos envolvidos consideram desnecessário se estender muito nessa unidade. As revistas Nutrire e Alimentos e Nutrição chegam a limitar a quantidade de parágrafos para a unidade de Introdução, denotando, assim, a necessidade de clareza e objetividade na construção dessa unidade. Destarte, percebemos que as Introduções analisadas corresponderam às expectativas dos periódicos, mostrando-se, em sua grande maioria, concisas, claras e objetivas.

Em conformidade com os membros experientes da área e com as orientações dos periódicos, a unidade de Introdução se caracteriza pela apresentação da pesquisa, delimitando-a e justificando a sua relevância. Para isso, os autores lançam mão de uma breve revisão de literatura pertinente ao tema abordado, levando em consideração as questões que norteiam o estudo, e, por vezes, utilizam-se da apresentação de lacunas teóricas existentes. Esse caminho teórico que garante a pertinência do estudo conduz à apresentação clara dos objetivos. Por outro lado, as recomendações do ICMJE (2014) estabelecem que, nessa unidade, não é cabível a apresentação de dados e conclusões.

Nesse sentido, vejamos como as unidades informacionais ${ }^{15}$ se fizeram presentes nas Introduções dos artigos acadêmicos analisados.

\footnotetext{
${ }^{14}$ Refere-se aos Colaboradores envolvidos na pesquisa, sendo designada uma numeração que corresponde a um membro experiente, que vai do 1 ao 7 . Os colaboradores de 1 a 4 responderam a entrevistas, enquanto os de 5 a 7 , a questionários.

${ }^{15}$ Unidades informacionais são blocos de informação que compõem a organização retórica de exemplares do gênero. Estas unidades tornar-se-ão movimentos ou passos retóricos caso alcance o critério de recorrência/prototipicidade.
} 
Quadro 3: Frequência de unidades informacionais em Introduções de artigos originais da cultura disciplinar da área de Nutrição

Movimento 1 - Apresentando informações gerais

(1) Referência ao conhecimento estabelecido no campo

(2) Referência aos principais problemas de pesquisa

Movimento 2 - Revisando pesquisas relacionadas

(1) Referência à pesquisa anterior

(2) Referência às limitações da pesquisa

Movimento 3 - Apresentando nova pesquisa

(1) Referência aos objetivos da pesquisa

(2) Referência ao principal procedimento de pesquisa
0\%

63,33\% (19 ocorrências)

100\% (30 ocorrências)

36,66\% (11 ocorrências)

100\% (30 ocorrências)

Fonte: Com base nos movimentos e passos propostos por Nwogu (1997, p. 135)

Na seção de Introdução, o modelo que mais se adequou ao nosso corpus foi o proposto por Nwogu (1997), considerando que houve a ocorrência dos três movimentos propostos pelo autor, embora a redefinição terminológica e estrutural da unidade proposta por Costa (2015) também venha a ser importante na construção de nosso modelo.

Assim como Costa (2015), consideramos relevante apresentar uma terminologia que expresse o mais claramente a função retórica das unidades informacionais; além disso, baseando-nos em Biasi-Rodrigues (1998), Bernardino (2000), Bezerra (2001), Costa (2015), entre outros autores, acreditamos que a utilização de verbos no gerúndio constrói mais adequadamente a indicação da ação retórica dos movimentos e passos. Para a organização de nossa proposta de configuração retórica, levamos em consideração a ordem mais recorrente ${ }^{16}$ desses movimentos e passos. Apresentamos, a seguir, um possível padrão para a seção de Introdução de artigos acadêmicos originais da área de Nutrição.

Quadro 4: Descrição retórica da unidade de Introdução de artigos originais da cultura disciplinar da área de Nutrição

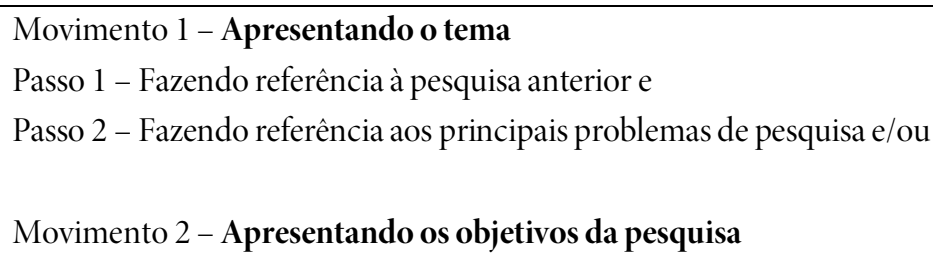

Fonte: de nossa autoria.

De acordo com o quadro 4, o primeiro movimento, Apresentando o tema, foi evidenciado por meio de dois passos, Fazendo referência à pesquisa anterior e Fazendo referência aos principais problemas de pesquisa. Embora não recorrente, o passo Referências às limitações da pesquisa (NWOGU, 1997), em alguns exemplares, fez-se pertinente na construção dessa apresentação da temática em estudo. Já o segundo movimento, Apresentando os objetivos da pesquisa, não foi constituído de passos, já que tal unidade informacional se faz presente, em grande parte dos artigos analisados, no final da introdução de forma clara, sucinta, e, em algumas vezes, destacada. Em suma, percebemos que a seção de Introdução, geralmente, lança mão de um percurso teórico referente ao tema estudado, direcionando aos problemas que norteiam a pesquisa, que, por sua vez, estabelecem os objetivos a serem alcançados com o estudo em curso. Analisemos, então, como essa unidade se apresenta por meio de seus movimentos e passos, conforme sua recorrência descrita no quadro 4.

\footnotetext{
${ }^{16}$ Neste trabalho, consideramos recorrente a frequência de unidades retóricas, movimentos e passos igual ou superior a $50 \%$ nos artigos analisados.
} 
O passo 1, Fazendo referência à pesquisa anterior, do primeiro movimento, Apresentando o tema, caracteriza-se por situar a pesquisa, mostrando um pouco do "estado da arte", como bem pontuou um dos membros experientes da área (C3). Esse passo se mostrou muito importante na construção dessa unidade retórica, tendo em vista não existir, nos exemplares analisados, uma seção específica para a revisão de literatura. Destarte, conforme a Revista de Nutrição, podemos evidenciar que a área de Nutrição julga pertinente uma discussão teórica pormenorizada, apenas, em artigos específicos para tal fim, os artigos de revisão ou metanálise. Nesse sentido, acreditamos que esse passo tem por objetivo fazer um recorte de pesquisas anteriores relevantes para seu estudo, não sendo cabível uma revisão extensa da literatura, tendo em vista esse passo compor uma unidade breve e concisa. Nessa direção, Pereira (2014) ${ }^{17}$, em seu manual sobre a produção de artigos científicos na área da Saúde, revela não ser necessária uma exaustiva apresentação de referências, mas, sim, uma síntese de estudos que darão suporte aos objetivos do trabalho.

Desse modo, o referido passo evidenciou-se, principalmente, pela citação de autores através de índices numéricos sobrescritos que direcionam para a seção de Referências (exemplos 01 e 02) ${ }^{18}$. No entanto, houve algumas ocorrências cujas citações se deram pela nominalização dos autores, ora apresentada no corpo do texto, ora entre parênteses (exemplos 03 e 04). Embora em menor número de ocorrência, foi evidente, ainda, a citação, concomitantemente, por meio do nome dos autores e por meio da numeração sobrescrita (exemplo 05).

(1) A Leucemia Linfoide Aguda (LLA) é o tipo mais comum de câncer infantil, constituindo cerca de um terço de todas as neoplasias malignas da criança ${ }^{5}$. Constitui uma doença maligna que resulta na produção descontrolada de blastos de origem linfoide e no bloqueio da produção normal de glóbulos vermelhos, brancos e plaquetas ${ }^{6}$. [...](AAON01)

(2) Lactose é um carboidrato encontrado exclusivamente no leite. É sintetizado nas glândulas mamárias e hidrolisado em glicose e galactose pela enzima lactase, também denominada lactase-florizina hidrolase, no intestino delgado. A presença de manifestações clínicas gastrointestinais decorrentes da má absorção da lactose é denominada intolerância à lactose (IL). Diversas situações podem causar redução na síntese da lactase, com consequente má absorção de lactose. Essas situações são classificadas como deficiência de lactase primária, secundária ou congênita. ${ }^{1,2}[\ldots]$ (AAON09)

(3) Segundo Abreu et al. (2009) as refeições principais (almoço, jantar e ceia) devem conter de 600 a 800 calorias e devem corresponder à faixa de 30\% a 40\% do Valor Energético Total (VET) diário, admitindo-se um acréscimo de 20 \% em relação ao VET de 2 mil calorias por dia. As refeições menores (desjejum e lanche) devem conter de 300 a 400 calorias e devem corresponder à faixa de 15\% a 20\% do VET diário, admitindo-se acréscimo de 20\% (400 calorias) em relação ao VET de 2000 calorias por dia. (AAON19)

(4) Um dos grupos populacionais mais vulneráveis às anemias nutricionais é o das gestantes (VASCONCELOS et al., 2008). Estima-se que de cada dez gestantes que fazem o pré-natal três sejam anêmicas (COSTA et al., 2009). A Organização Mundial da Saúde (OMS) define anemia na gestação como uma concentração de hemoglobina inferior a $11 \mathrm{~g} / \mathrm{dL}$ e hematócrito menor que 33\% (WHO, 2001). (AAON20)

(5) Roongpisuthipong et al., ${ }^{8}$ em seu estudo com indivíduos cirróticos em diferentes estágios da doença e diferentes etiologias, encontraram uma prevalência de DPC em doenças hepáticas entre 10\% e 100\%. Essa prevalência aumenta à medida em que a gravidade da doença aumenta, ou seja, a DPC é muito mais prevalente em pacientes Child C do que nos pacientes Child A e B. [...] (AAON07)

Os exemplos de 01 a 05 confirmam as considerações de Costa (2015) para esse passo, mostrando que a citação pode ocorrer em três situações diversas, pela nominalização dos autores, também, evidente nas proposições de Nwogu (1997), pela indicação numérica que direciona para a unidade de Referências, bem como pela utilização combinada das duas formas. No entanto, consideramos um padrão prototípico para área de Nutrição e Saúde a citação por meio de numeração sobrescrita, levando em consideração que os periódicos da área orientam os autores a seguirem as normas internacionais propostas pelo ICMJE.

\footnotetext{
${ }^{17}$ Para a discussão das unidades informacionais presentes nos artigos analisados, contamos, ainda, com as considerações de Pereira (2014) sobre a produção de artigos científicos na área da Saúde, principalmente, no que se refere às informações mais prototípicas das seções retóricas do referido gênero.

${ }^{18}$ Nos excertos apresentados neste trabalho, destacamos, em negrito, os itens léxico-gramaticais mais representativos, que serão apresentados no final da descrição de cada unidade informacional.
} 
Ainda, em relação a esse passo, evidenciamos que os autores, geralmente, lançam mão de dados oriundos não só de pesquisas acadêmicas, mas também de estudos provenientes de institutos, órgãos governamentais, agências especializadas, entre outros órgãos (exemplos 04, 06 e 07). O C3 confirma essa característica ao revelar que os artigos acadêmicos são fontes confiáveis, haja vista apresentarem resultados de pesquisas acadêmicas, bem como resultados provenientes de estudos de órgãos nacionais e internacionais, como OMS, UNICEF, entre outros.

(6) A OMS preconiza o controle no consumo de alimentos que contenham GTr, com objetivo de reduzir o risco e aumentar a efetividade do tratamento da DCV, e aconselha que o consumo de GTr seja inferior a 1\% das calorias totais da dieta. ${ }^{5}$ (AAON06) (7) A Pesquisa Nacional sobre Saúde e Nutrição (PNSN), realizada pela Fundação Instituto Brasileiro de Geografia e Estatística (IBGE) em 1989, revelou que 7,7\% dos adolescentes brasileiros apresentavam sobrepeso. ${ }^{6}$ Outros estudos desenvolvidos com adolescentes do país, na última década, demonstram prevalências todavia superiores. ${ }^{9,10}$ (AAON26)

Desse modo, sugerimos que, para a área de Nutrição, esses dados de pesquisas que ocorrem fora das universidades são considerados fontes teóricas tanto quanto aquelas advindas da academia. Em suma, esse passo vem apresentar o levantamento teórico que os autores consideram relevantes para seu estudo, confirmando, assim, as proposições de Swales (1990) acerca da unidade informacional, Revisar a Literatura, em introduções de artigos.

No que se refere às marcas léxico-gramaticais, quando esse passo se realizou por meio de uma definição ou conceituação, o verbo apresentou-se, geralmente, no presente do indicativo, e com certa frequência utilizou-se o verbo "ser" (exemplos 01 e 02). Por outro lado, quando se fez por meio da apresentação de dados de uma pesquisa, optou-se por utilizar verbos no pretérito perfeito (exemplo 05). Evidenciamos, ainda, a ocorrência de verbos na voz passiva, seja na forma analítica, seja na sintética, bem como a frequência de locuções com verbos modais "poder e dever" (exemplo 03). Nessa unidade informacional, não foi possível evidenciar uma marca terminológica aparente que contemplasse a sua função retórica.

Já o passo 2, Fazendo referência aos principais problemas de pesquisa, do primeiro movimento, Apresentando o tema, segundo o C1, caracteriza-se pela apresentação clara das questões que impulsionam o estudo, corroborando, assim, as orientações de Pereira (2014), que considera relevante informar o problema de pesquisa para justificar a investigação. Nesse sentido, esse passo funcionou como uma ponte de ligação entre a fundamentação teórica e a apresentação dos objetivos da pesquisa, conforme verificamos nos exemplos de 08 a 12.

(8) Desse modo, a avaliação do estado nutricional de adolescentes tem sido recomendada, permitindo identificar os subgrupos com maior frequência de exposição a esse desfecho, que poderão ser alvo de intervenções para avaliação dos níveis de saúde da população jovem. (AAON02)

(9) Considerando que a deficiência primária de lactase é bastante comum na população, é esperado que uma importante parcela destes indivíduos desenvolva IL. Sendo o manejo clínico desta situação eminentemente nutricional, o nutricionista passa a ser um profissional fundamental no tratamento; por isso, seu conhecimento acerca das possibilidades de adaptações nutricionais necessárias na alimentação desses indivíduos é fundamental. (AAON09)

(10) Nesse contexto de priorização do tema no âmbito das políticas públicas, o monitoramento de indicadores referentes às práticas alimentares do início da vida é fundamental, pois pode subsidiar o desenvolvimento, a avaliação e o redirecionamento de tais políticas ${ }^{3}$. (AAON22)

(11) Assim, a abordagem do agregado familiar e, particularmente, do pareamento mãe-filho biológico, representa uma oportunidade muito peculiar de estudo, seja pela rapidez das mudanças produzidas no perfil nutricional, seja pelo interesse em compreender e atuar nas políticas públicas a partir de um enfoque familiar. Seriam os casos do Programa Saúde da Família (PSF) e da segurança alimentar do Programa Bolsa Família (PBF), que praticamente atendem a metade da população brasileira ${ }^{13,14}$. Nesse contexto, o estado de saúde do núcleo familiar mais exposto aos desvios nutricionais, crianças e mães, pode oferecer subsídios importantes sobre questões que interessam diretamente às políticas públicas dirigidas para a segurança alimentar e nutricional. (AAON25)

(12) Portanto, identificar as famílias mais vulneráveis à insegurança alimentar e compreender suas causas e seus efeitos são fundamentais para encontrar formas viáveis de solução do problema.-6 ${ }^{4-6 A N 28)}$ 
É interessante ressaltar que esse passo se fez prototípico na área de Nutrição, alinhando-se aos dados levantados por Nwogu (1997) para a área de Medicina. Por outro lado, Costa (2015) não evidencia uma recorrência para esse passo. Em relação a essa incongruência, devemos levar em consideração que a área de Medicina é dividida em três subáreas de avaliação (Medicina I, Medicina II e Medicina III), ${ }^{19}$ levando-nos a hipotetizar sobre a existência de uma flutuação de blocos informacionais de uma subárea para outra. De acordo com as considerações do C6, a área de Nutrição está mais voltada para pesquisas que emergem das necessidades pelas quais passam a sociedade, avaliando, assim, o impacto de determinados hábitos alimentares e estilo de vida dos mais variados grupos populacionais. Desse modo, acreditamos que o viés mais aplicado da área de Nutrição conduz os autores à apresentação de uma problematização que, por sua vez, respalda a necessidade de seu estudo.

Por outro lado, os autores, na construção desse passo, muitas vezes não estabeleceram uma delimitação precisa, de modo que esse bloco informacional e o outro, Apresentando os objetivos da pesquisa, se mostraram intimamente ligados (exemplo 13), apresentando, assim, uma linha divisória tênue entre eles.

(13) Considerando-se a importância da obesidade, sua forte participação na determinação de outros riscos cardiometabólicos e a existência de um subgrupo de indivíduos obesos que não apresentam outros fatores de risco cardiometabólico, [procurou-se analisar a associação entre práticas alimentares com maior ação preventiva e baixo risco cardiometabólico em mulheres obesas, com o propósito de orientar ações preventivas de outros riscos para a saúde da população obesa.] (AAON27)

Esse passo denota sua função retórica por meio do item lexical "importante" (exemplos 09 e 11) e suas derivações, bem como faz uso de formas verbais no infinitivo (exemplos de 10 a 13). Salientamos, ainda, que tal unidade informacional, geralmente, inicia-se por elementos coesivos (exemplos de 08 a 13), promovendo uma retomada da informação mais importante apresentada na revisão de literatura.

O segundo movimento, Apresentando os objetivos da pesquisa, mostrou-se essencial à unidade de Introdução, pois é por meio dele que o autor contextualiza o seu estudo dentro da temática apresentada, e, ao mesmo tempo, respalda a necessidade de sua pesquisa. O C3, por exemplo, sugere que o autor, ao mostrar os objetivos do seu estudo, tenta "vender a ideia de que seu trabalho é importante". Esse bloco informacional apresentou-se, predominantemente, no final da seção de Introdução, o qual não ultrapassou o limite de um parágrafo para tal fim, confirmando, assim, as orientações dos periódicos que consideraram pertinente concluir tal unidade com a apresentação sucinta dos seus objetivos. Pereira (2014) confirma esses dados ao indicar que no final da Introdução deve-se mostrar o objetivo da investigação.

Nesse sentido, o referido movimento foi marcado, predominantemente, pela expressão "objetivo" e suas variações (exemplos de 14 a 16), acompanhada de verbos no infinitivo, corroborando os dados aventados por Costa (2015) e as orientações da revista Cadernos de Saúde Pública que considera pertinente a apresentação dos objetivos por meio do uso de verbos no infinitivo. É importante sublinhar que o uso do infinitivo em apresentação de objetivos não corresponde a uma característica exclusiva das áreas de Nutrição e Medicina, mas da comunidade acadêmica de um modo geral. Na construção desse movimento, os autores utilizaram, principalmente, verbos indicando uma ação passada com o auxílio da forma verbal no infinitivo (exemplos 14 e 15), salvo poucos exemplares que se mostraram no tempo presente (exemplo 16), destoando das proposições de Nwogu (1997).

(14) O presente artigo objetivou avaliar a qualidade da alimentação de pré-escolares beneficiados pelo Programa Bolsa Família (PBF), do município de Viçosa-MG, segundo a situação de (in)segurança alimentar do domicílio. (AAON11)

(15) Portanto, o objetivo desta pesquisa foi sistematizar um percurso para o desenvolvimento de receitas com redução de fenilalanina, com qualidade nutricional e sensorial, permitidas para o tratamento da fenilcetonúria. (AAON12)

(16) O presente estudo tem como objetivo apresentar a prevalência de insegurança alimentar em famílias da cidade de Pelotas, Rio Grande do Sul, bem como descrever o estado nutricional dos membros dessas famílias em insegurança alimentar. (AAON21)

${ }^{19}$ Ver documento da CAPES sobre as áreas de avaliação. 
Em suma, o segundo movimento, Apresentando os objetivos da pesquisa, indica de forma clara e sucinta os propósitos do estudo. É interessante sublinhar que tal bloco de informação surge no final da unidade de Introdução para que se mostre, explicitamente, o propósito do estudo, considerando que tal informação será retomada em vários momentos da pesquisa.

Antes de concluirmos a descrição da unidade retórica de Introdução, vejamos como se apresentou a unidade informacional, Referência às limitações de pesquisa, proposta por Nwogu (1997) e confirmada por Costa (2015). Embora essa unidade não tenha sido recorrente no corpus, em alguns exemplares, foi substancial para a construção da contextualização da pesquisa, validando a necessidade de se realizar o referido estudo. Essa unidade foi marcada, em sua maioria, por expressões que denotam a ausência ou a insuficiência de estudos na área (exemplos de 17 a 19), assim como foi notado por Costa (2015).

(17) Os estudos sobre gestão do PNAE, bem como da eficiência e da eficácia do Programa ainda são escassos no Brasil ${ }^{3}$ e em Santa Catarina ${ }^{13}$. Uma pesquisa desenvolvida pelo Instituto Nacional de Estudos e Pesquisas Educacionais (INEP), com o objetivo de avaliar o processo de descentralização financeira do PNAE no ano de 1997, mostrou uma tendência de uniformidade e cumprimento das metas de qualidade e quantidade da alimentação escolar em todo o Brasil, porém não buscou associação entre os dados das diferentes regiões do Brasil e seus estados ${ }^{14}$. (AAON03)

(18) A literatura é escassa em estudos que discutem as etapas de desenvolvimento de novas receitas para esses pacientes, apesar da crescente exigência do consumidor por alimentos especiais, com qualidade nutricional e sensorial. (AAON12)

(19) Apesar da relevância do tema, ainda são escassos os estudos que avaliam comparativamente o padrão alimentar de crianças que vivem em áreas geográficas circunvizinhas, com diferentes características socioeconômicas e ambientais ${ }^{10,11}$, a exemplo dos espaços urbanos e rurais de municípios baianos. (AAON24)

Conforme os exemplos de 17 a 19, a referida unidade informacional teve como principal função inserir na contextualização do tema a escassez de trabalhos na literatura, que, por sua vez, justifica a necessidade de um estudo aprofundado do assunto. Essas observações confirmam as proposições de Pereira (2014) de que uma pesquisa também se justifica pela possibilidade de acrescentar ou ampliar um assunto pouco estudado. A apresentação dessas lacunas teóricas não foi evidenciada somente pela ausência total de estudos, mas também pela urgência de se buscar mais dados acerca de uma determinada variante, assim como no exemplo 17, ao apontar para a necessidade de um estudo que faça uma "associação entre os dados das diferentes regiões do Brasil e seus estados".

De acordo com o nosso corpus, os artigos da área de Nutrição apresentaram um modelo retórico mais próximo ao encontrado por Nwogu (1997), seguindo, em grande parte dos exemplares, um padrão prototípico, fazendo primeiramente uma revisão da literatura, que, por sua vez, gera uma problematização, direcionando, assim, aos objetivos da pesquisa. Por vezes, os autores recorreram à apresentação de lacunas teóricas; no entanto, tal unidade não se fez recorrente em nossos exemplares. Desse modo, sugerimos que, na área de Nutrição, a Introdução se configura como uma seção breve, concisa, porém de grande relevância na construção de artigos acadêmicos, tendo em vista, ainda, que nessa área não há uma unidade retórica destacada para a revisão de literatura.

Para concluir a unidade de Introdução, apresentamos um quadro com as marcas léxico-gramaticais das unidades informacionais que se fizeram presentes no corpus analisado. 
Quadro 5: Apresentando itens léxico-gramaticais da unidade retórica de Introdução

Movimento 1: Apresentando o tema

Passo 1 - Fazendo referência à pesquisa anterior

\begin{tabular}{|c|c|}
\hline Tipo de item & Exemplos \\
\hline Verbos no presente & $\begin{array}{l}\text { Aconselha, consiste, constitui, dá, define, demonstram, destaca-se, destacam, destacam-se, distribui, é, } \\
\text { encontra-se, entende, estima, estima-se, existem, ocasionam, observa-se, preconiza, pode, podem, } \\
\text { possibilita, possuem, promovem, recomenda, refere-se, representam, são, tem. }\end{array}$ \\
\hline Verbos no pretérito & $\begin{array}{l}\text { Apontou, apontaram, apresentaram, atingiu, definiu, deixou, encontrou, encontraram, foi, lançou, } \\
\text { melhorou, resultou, sofreu. }\end{array}$ \\
\hline Verbos modais & Pode $(m)$ apresentar, podem ser encontradas, devem corresponder, deve ser, pode levar. \\
\hline Locuções verbais & Têm sido descritos, vem sendo apontado, vem aumentando, vem se tornando, têm demonstrado \\
\hline Voz passiva & $\begin{array}{c}\text { São usados, são utilizadas, é apontada, são apontadas, é definida, é marcado, é potencializado, sabe-se, } \\
\text { constitui-se. }\end{array}$ \\
\hline
\end{tabular}

Movimento 1: Apresentando o tema

Passo 2 - Fazendo referência aos principais problemas de pesquisa

\begin{tabular}{c|c}
\hline Tipo de item & Exemplos \\
\hline $\begin{array}{c}\text { Expressão denotativa de } \\
\text { relevância do estudo }\end{array}$ & Fundamentais, importância, importante. \\
\hline $\begin{array}{c}\text { Uso de Locuções verbais e } \\
\text { do infinitivo }\end{array}$ & A fim de verificar, identificar, pode oferecer, pode revelar, pode subsidiar, procurando esclarecer. \\
\hline Termos coesivos & Desse modo, considerando que, nesse sentido, assim, tendo em vista, dada a, nesse contexto, portanto. \\
\hline
\end{tabular}

Movimento 2: Apresentando os objetivos da pesquisa

\begin{tabular}{c|c}
\hline Tipo de item & Exemplos \\
\hline $\begin{array}{c}\text { Expressão denotativa da } \\
\text { função retórica }\end{array}$ & Objetivo, objetivou, objetiva, objetivando, tem como objetivo, propósito. \\
\hline $\begin{array}{c}\text { Uso de verbos no tempo } \\
\text { passado com/sem auxílio } \\
\text { do infinitivo }\end{array}$ & $\begin{array}{c}\text { Foi: avaliar, identificar, investigar, realizado, sistematizar, verificar, caracterizar; objetivou explorar, } \\
\text { procurou-se analisar, teve como objetivo apresentar, teve como objetivo comparar, teve como objetivo } \\
\text { descrever. }\end{array}$ \\
\hline
\end{tabular}

Movimento 2: Revisando pesquisas relacionadas

Passo 2 - Referência às limitações de pesquisas (NWOGU, 1997)

\begin{tabular}{c|c}
\hline Tipo de item & Exemplos \\
\hline $\begin{array}{c}\text { Expressão denotativa da } \\
\text { função retórica }\end{array}$ & $\begin{array}{c}\text { Escassez de estudos, faltam estudos, literatura escassa, nenhum estudo, poucos estudos; verifica-se um } \\
\text { desconhecimento. }\end{array}$
\end{tabular}




\section{CONSIDERAÇÕES FINAIS}

Por meio do diálogo com a literatura, com as orientações dos periódicos e com o olhar de expertise dos membros experientes da área de Nutrição, evidenciamos que a Introdução se mostra uma unidade retórica breve, concisa e objetiva, no entanto, fundamental na configuração de artigos acadêmicos na área de Nutrição, considerando, ainda, que não há uma unidade retórica voltada exclusivamente para a revisão de literatura.

Nessa unidade retórica, o tema é apresentado por meio de uma breve revisão de literatura, evidenciando, apenas, as referências teóricas que os autores consideram mais relevantes para a construção do seu estudo. Notamos, ainda, que os autores lançam mão de resultados oriundos de estudos de órgãos nacionais e internacionais, como OMS, UNICEF, entre outros, revelando-nos que, para a área de Nutrição, esses dados de pesquisas que ocorrem fora das universidades são considerados fontes teóricas tanto quanto aquelas advindas da academia. A partir dessa revisão temática, as questões que impulsionaram o estudo são reveladas, justificando, assim, a necessidade de desenvolver tal empreendimento investigativo.

Diante dos resultados, constatamos que a configuração sociorretórica de Introduções em artigos acadêmicos originais da cultura disciplinar da área de Nutrição aproximou-se das descrições da área de Medicina propostas por Nwogu (1997) e Costa (2015), levando-nos a inferir que essa padronização pode ser regular na grande área da Saúde. No entanto, tal generalização carece de estudos mais aprofundados nas demais áreas da Saúde, para confirmar ou não essa hipótese.

Acreditamos, ainda, que os resultados alcançados nesse estudo venham fornecer subsídios à cultura disciplinar da área de Nutrição no que se refere ao letramento acadêmico, considerando o desenho descritivo da unidade retórica de Introdução em artigos originais da área de Nutrição e do uso que os seus membros fazem do referido gênero.

\section{REFERÊNCIAS}

ALIMENTOS E NUTRIÇÃO. Instruções aos autores. Disponível em: <http://serv-bib.fcfar.unesp.br/seer/index.php/alimentos>. Acesso em: 29 maio 2015.

AMIRIAN, Z; KASSAIAN, Z:; TEVAKOLI, M. Genre analysis: an investigation of the Discussion sections of Applied Linguistics research articles. The Asian ESP Journal, Isfahan, v. 4, n. 1, p. 39-63, abr. 2008.

ASKEHAVE, I.; SWALES, J. M. Identificação de gênero e propósito comunicativo: um problema e uma possível solução. In: BEZERRA, B. G.; BIASI-RODRIGUES, B.; CAVALCANTE, M. M. (Org.). Gêneros e sequências textuais. Recife: Edupe, 2009. p. 221-247.

BAWARSHI, A. S.; REIFF, M. J. Gênero: história, teoria, pesquisa e ensino. Tradução de Benedito Gomes Bezerra et al.São Paulo: Parábola, 2013.

BERNARDINO, C. G. Depoimentos dos alcóolicos anônimos: um estudo do gênero textual. 2000. 162f. Dissertação (Mestrado em Linguística) - Universidade Federal do Ceará, Fortaleza, 2000.

O metadiscurso interpessoal em artigos acadêmicos: espaço de negociações e construção de posicionamentos. 2007. 243f. Tese (Doutorado em Linguística Aplicada) - Universidade Federal de Minas Gerais, Belo Horizonte, 2007.

BEZERRA, B. G. A distribuição das informações em resenhas acadêmicas. 2001. 141f. Dissertação (Mestrado em Linguística) Universidade Federal do Ceará, Fortaleza, 2001. 
BHATIA, V. K. Worlds of written discourse: a genre-based view. London, Continuum, 2004.

BIASI-RODRIGUES, B. Estratégias de condução de informações em resumos de dissertações. 1998. 307f. Tese (Doutorado em Linguística) - Universidade Federal de Santa Catarina, Florianópolis, 1998.

CADERNO DE SAÚDE PÚBLICA. Instruções para autores. Disponível em: <http://cadernos.ensp.fiocruz.br/csp/portal/>. Acesso em: 06 jun. 2015.

. Sobre o CFN. Disponível em: <http://www.cfn.org.br/index.php/sobre-nos/>. Acesso em: 26 nov. 2014.

COORDENAÇÃO DE APERFEIÇOAMENTO DE PESSOAL DE NÍVEL SUPERIOR. Relatório do I Seminário de acompanhamento de Programas de Pós-Graduação da área de Nutrição. Brasília, 2012, 9p. Disponível em: <http://www.capes.gov.br/component/content/article/44-avaliacao/4689-nutricao>. Acesso em: 26 nov. 2014.

Documento de área 2013. Área de avaliação: Nutrição. 2013a, 38p. Disponível em: <http://www.capes.gov.br/component/content/article/44-avaliacao/4689-nutricao>. Acesso em: 26 nov. 2014.

Relatório de avaliação trienal 2010 - 2012. Área de avaliação: Nutrição. 2013b, 23p. Disponível em: <http:/www.capes.gov.br/component/content/article/44-avaliacao/4689-nutricao>. Acesso em: 27 maio 2015.

. Sobre as áreas de avaliação. Disponível em: <http://www.capes.gov.br/avaliacao/sobre-as-areas-de-avaliacao >. Acesso em: 27 maio 2015 .

Webqualis. Disponível em: <http://qualis.capes.gov.br>. Acesso em: 27 maio 2015.

COSTA, R. L. S. da. Culturas disciplinares e artigos acadêmicos experimentais: um estudo comparativo da descrição sociorretórica. 2015. 242f. Dissertação (Mestrado Acadêmico) - Universidade Estadual do Ceará, Fortaleza, 2015.

DIAS, F. G. R.; BEZERRA, B. G. Análise retórica de introduções de artigos científicos da área da saúde pública. Horizontes de Linguística Aplicada, Brasília, ano 12, n. 1, p. 163-182, 2013.

EPIDEMIOLOGIA E SERVIÇOS DE SAÚDE PÚBLICA. Normas para publicação. Disponível em: <http://scielo.iec.pa.gov.br/revistas/ess/pinstruc.htm>. Acesso em: 04 jun. 2015.

HENDGES, G. R. Novos contextos, novos gêneros: a seção de Revisão da Literatura em artigos acadêmicos eletrônicos. 2001. $138 f$. Dissertação (Mestrado em Letras) - Universidade Federal de Santa Maria, Santa Maria, 2001.

HYLAND, K. Scientific claims and community values: articulating an academic culture. Language \& Communication, United Kingdom, v. 17, n 1, p. 19-31, 1997.

. Disciplinary discourse: social interactions in academic writing. Singapura: Pearson Education Limited, 2000.

INTERNATIONAL COMMITTEE OF MEDICAL JOURNAL EDITORS. Recommendations for the conduct, reporting, editing, and publication of scholarly work in medical journals. 2014, 17p. Disponível em: < http://www.icmje.org/icmjerecommendations.pdf $>$. Acesso em: 11 abr. 2015.

MOTTA, D. G. da; OLIVEIRA, M. R. M. de; BOOG, M. C. F. A formação universitária em nutrição. Pro-Posições, Campinas, v. 14, n. 1, 69-86, jan./abr. 2003. 
MOTTA-ROTH, D.; HENDGES, G. R. Produção textual na universidade. São Paulo: Parábola Editorial, 2010.

NUTRIRE. Instrução aos autores. Disponível em: <http://www.revistanutrire.org.br/>. Acesso em: 03 jun. 2015.

NWOGU, K. N. The Medical research paper: structure and functions. English for Specific Purposes, Washington, v. 16, n. 2, p. 119-138, 1997.

PEREIRA, M. G. Artigos científicos: como redigir, publicar e avaliar. Rio de Janeiro: Guanabara Koogan, 2014.

REVISTA DE NUTRIÇÃO. Instrução aos autores. Disponível em: <http://www.scielo.br/revistas/rn/pinstruc.htm>. Acesso em: 28 maio 2015.

SCIENTIA MEDICA. Instruções para autores. Disponível

<http://revistaseletronicas.pucrs.br/fo/ojs/index.php/scientiamedica>. Acesso em: 28 maio 2015.

SILVA, L. F. Análise de gênero: uma investigação da seção de Resultados e Discussão em artigos científicos de Química. 1999. 111 . Dissertação (Mestrado em Letras) - Universidade Federal de Santa Maria, Santa Maria, 1999.

SWALES, J. M. Genre analysis: English in academic and research settings. Cambridge: Cambridge University Press, 1990.

Research genres: explorations and applications. New York: Cambridge: Cambridge University Press, 2004.

. Repensando gêneros: nova abordagem ao conceito de comunidade discursiva. In: BEZERRA, B. G.; BIASI-RODRIGUES,

B.; CAVALCANTE, M. M. (Org.). Gêneros e sequências textuais. Recife: Edupe, 2009. p. 197-220.

SWALES, J. M.; FEAK, C. B. English in today's research world: a writing guide. Ann Arbor: The University of Michigan Press, 2000. 